\title{
THE ASSOCIATION BETWEEN POLYCYSTIC OVARY SYNDROME AND LIPID ACCUMALATION PRODUCT INDEX
}

\author{
Halime Kılıç${ }^{1}$, Kenan Çadırcı' ${ }^{2}$, Şenay Durmaz ${ }^{3}$, Mustafa Utlı², Hakan Sevimli ${ }^{2}$, Ayşe Çarlıoğlư
}

\author{
${ }^{1}$ Nene Hatun Maternity Hospital, Erzurum, TURKEY \\ ${ }^{2}$ Department of İnternal Medicine, Erzurum Training and Research Hospital, Erzurum, TURKEY \\ ${ }^{3}$ Department of İnternal Medicine, Kırıkkale University Faculty of Medicine, Kırıkkale, TURKEY
}

\section{Introduction}

The polycystic ovary syndrome (PCOS) is an important cause of both menstrual irregularity and androgen excess in women. When fully expressed (for example, in women with hirsutism, irregular menstrual cycles, obesity, and a classic ovarian morphology on transvaginal ultrasound), PCOS can be readily diagnosed. The lipid accumulation product (LAP) index which is associated with abnormal glucose regulation can be easily calculated. Women with polycystic ovary syndrome have more than one risk factor for the development of cardiovascular diseases such as glucose intolerance, insulin resistance and abdominal lipoidosis. In this study, we intend the evaluation of LAP index in women with PCOS.

\section{Method}

Thirty-five women with PCOS (mean age 22,4 $4,5,2$ year) and 33 healthy normoovulatory women in control group who had similar age (mean age 21,0 $\pm 3,1$ year) included in our study.

The plasma lipid profile, glucose and insulin levels of the patients were detected after 12 hours fasting and waist circumference was measured. All hormonal and biochemical analysis were performed by automatic analyzer. The lipid accumulation product index was calculated with the formula previously defined as below

[waist circumference $(\mathrm{cm}) \quad-\quad 58] \times$ triglycerides concentration (mmol/l) for men and

[waist circumference $(\mathrm{cm})-65] \times$ triglycerides concentration (mmol/l) for women.

HOMA IR glucose was calculated with the formula of (mmol/L)x insulin $(\mu \mathrm{U} / \mathrm{ml}) / 22.5$.
Results

In our study, the mean of LAP index in the patients and the control group were respectively $(38,2 \pm 42,6$ and $12,0 \pm 13.1$, $\mathrm{p}=0,000)$, TG $(115,9 \pm 67,9 \mathrm{mg} / \mathrm{dl}$ and $82,8 \pm 46,3 \mathrm{mg} / \mathrm{dl}$, $\mathrm{p}=0,004)$, HOMA-IR $(3,5 \pm 2,4$ and $2,2 \pm 1,3 \quad \mathrm{p}=0,01)$, total cholesterol( 178,2 $\pm 35,4 \mathrm{mg} / \mathrm{dl}$ and 160,0 $\pm 27,7 \mathrm{mg} / \mathrm{dl} p=0,02)$, insulin

$(6,1 \pm 10,1 \mu \mathrm{U} / \mathrm{ml}$ and $11,0 \pm 6,3 \mu \mathrm{U} / \mathrm{ml} \mathrm{p}=0,02)$, waist circumference $(84,3 \pm 15,8 \mathrm{~cm}$ and $69,2 \pm 8,05 \mathrm{~cm}, \mathrm{p}=$ $0,000)$, LDL-C $(107,1 \pm 31,1 \mathrm{mg} / \mathrm{dl}$ and $88,7 \pm 27,1 \mathrm{mg} / \mathrm{dl}$ $\mathrm{p}=0,01)$

There were positive correlation between LAP index and bodyweight ( $r=0,79 p=0,000)$, waist circumference $(r=0,81$ $p=0000)$ HOMA-IR score $(r=0,35 p=0,008)$, insulin ( $r=0,37$ $p=0,005)$, TG $(r=0,79 p=0,000)$ and LDL-C levels $(r=0,32 p=$ 0,008 )

The positive correlation were detected among BMI and LAP index $(r=0,73 p=0,000)$, HOMA-IR $(r=0,48 p=0,000)$, fasting insulin levels $(r=0,46 p=0,000)$ respecttively.

\section{Conclusion}

High LAP index may help for the evaluation of metabolic risk in women with PCOS. In our study, we also determined positive correlations LAP index and other metabolıc parameters.such as TG, LDL- C, HOMA-IR and fasting insulin levels. Increment of LAP may be associated with high cardiovascular risc. 